\title{
In vitro Screening of Antibacterial Potentials of Achyranthes aspera Azolla pinnata and Cissus quadrangularis
}

\author{
Tamanna Talreja ${ }^{1}$, Mangesh Kumar ${ }^{1}$, Asha Goswami ${ }^{2}$ and Tribhuwan Sharma ${ }^{1}$ \\ ${ }^{1}$ Department of Animal Nutrition, CVAS, Rajasthan University of Veterinary and \\ Animal Sciences, Bikaner (Rajasthan), India \\ ${ }^{2}$ M.L.B. Govt. College, Nokha, Bikaner (Rajasthan), India \\ *Corresponding author
}

\begin{tabular}{|c|c|}
\hline & A B S T R A C T \\
\hline Keywords & \multirow{4}{*}{$\begin{array}{l}\text { The present investigation was undertaken for in vitro screening of antibacterial activities of } \\
\text { different extracts (ethyl acetate, methanol and benzene) of various plant parts of } \\
\text { Achyranthes aspera, Azolla pinnata, Cissus quadrangularis. In vitro antibacterial efficacy } \\
\text { of plants selected was assessed by well diffusion method against pathogenic bacteria such } \\
\text { as Staphylococcus aureus, Pseudomonas aeruginosa and Escherichia coli. The ethyl } \\
\text { acetate extract of Cissus quadrangularis exhibited highest zone of inhibition against S. } \\
\text { aureus }(25 \pm 1.3 \mathrm{~mm}) \text { followed by Achyranthes aspera }(20.0 \pm 0.5 \mathrm{~mm}) \text { and Azolla pinnata } \\
(20 \pm 0.9 \mathrm{~mm}) \text { whereas Methanolic extract of plants selected also showed good results } \\
\text { against } P \text {. aeruginosa. None of activity is shown by Benzene extract against any test } \\
\text { pathogen. Results of the present investigation indicate that these plants possess compounds } \\
\text { with antibacterial properties and hence can be exploited for future natural plant based } \\
\text { antimicrobials. }\end{array}$} \\
\hline $\begin{array}{l}\text { Achyranthes aspera, } \\
\text { Azolla pinnata, } \\
\text { Cissus } \\
\text { quadrangularis, in } \\
\text { vitro screening. }\end{array}$ & \\
\hline Article Info & \\
\hline $\begin{array}{l}\text { Accepted: } \\
\text { 02 March } 2017 \\
\text { Available Online: } \\
10 \text { April } 2017\end{array}$ & \\
\hline
\end{tabular}

\section{Introduction}

Plants are capable of synthesizing variety of low molecular weight organic compounds, called secondary metabolites usually with very unique and complex structures. The role of secondary product has been rather ambiguous and earlier these were thought to be first waste materials. Now days, plant secondary metabolites are seen as tremendous source of pharmacological value for scientific and clinical research. Their biological activities have high therapeutic value, applicable in health care, drug development and synthesis of beneficial compounds. A number of plants have been screened for their antimicrobial properties especially due to the presence of secondary metabolites. In the present scenario of emergence of multidrug resistance to human pathogenic infections, it has become very necessary to search for new antimicrobial substances from other sources such as plants. Plants with their wide variety of chemical constituent offer a promising source of new antimicrobial agent, with general as well as specific antimicrobial activity (Nair et al., 2005; Luseba et al., 2007; Yadav et al., 2011).

Achyranthes aspera is an annual, stiff erect herb, and found commonly as a weed throughout India and prescribed in Ayurveda 
as an alternative, anthelmintic, dyspeptic, digestive, tonic, analgesic in eye and ear diseases and in the treatment of irregular menstruation, fever, dysentery and asthma. The chemical constituents show the presence of tannins, flavonoids, saponins, glycosides, steroids, terpenoids and alkaloids which are used in medicinal purpose. Azolla pinnata is a pteridophyte plant rich in protein used in mosquito and weed control and traditional medicine. Plant rich in secondary metabolites such as flavonoids, tannins, terpenoids and alkaloids have significant biological activity against pathogens (Bagavan et al., 2008; Pakrashi et al., 1977; Lakshmi et al., 2006). Cissus quadrangular is a succulent vine native to India. It is commonly known as asthisamharaka. The chemical constituents show the presence of tannin, phlobatannins, saponin, flavonoids, steroids, terpenoids, cardiac glycosides and anthroquinones which are used in medicinal purpose.

Keeping in mind the infectious diseases, resistant pathogenic organism and side effect of antibiotics an attempt was needed to be done to determine the antimicrobial activity of plant based medicinal agents. Therefore, the aim of the current research focuses to investigate the effects of various extracts of three plants Achyranthes aspera, Azolla pinnata and Cissus quadrangularis on growth of Staphylococcus aureus, Pseudomonas aeruginosa and Escherichia coli.

\section{Materials and Methods}

\section{Collection of plant material}

The Azolla had been cultivated at Livestock Feed Resource Management and Training Center, RAJUVAS, Bikaner, it was harvested, washed thoroughly, dried for 2 to 3 days under shed, grinded and packed in air tight bags whereas Cissus quadrangularis (stem) was collected from various parks of Bikaner where it was cultivated as an ornamental plant whereas seed samples of Achyranthes aspera (seeds) were purchased from the shop of herbal medicine and were identified by a well known taxonomist of Bikaner. The fresh sample of Cissus stem and seeds of Achyranthes was dried separately, grinded and used for further analysis.

\section{Preparation of extracts by solvent extraction}

Crude plant extract was prepared by soxhlet extraction method. Five grams of powdered Achyranthes aspera, Azolla pinnata, and Cissus quadrangularis was filled in thimble directly, were placed in soxhlet apparatus, and extracted separately using methanol, benzene and ethyl acetate for $24 \mathrm{hrs}$ or until the solvent in siphon tube of an extractor become colorless. The extracts were than concentrated in pre-weighted vials on a rotary evaporator below $50^{\circ} \mathrm{C}$. Dried extract was weighted and reconstituted with known volume of solvent and were stored in vials at $4{ }^{\circ} \mathrm{C}$ for further experimental studies.

\section{Screening of plant extracts for antimicrobial activity}

Antibacterial activities of different extracts were studied by the well diffusion method.

\section{Test organisms}

The pure cultures of bacteria maintained in the nutrient broth medium. The test organisms used are Staphylococcus aureus, Pseudomonas aeruginosa and Escherichia coli.

\section{Preparation of inoculums}

Stock cultures were maintained at $4^{\circ} \mathrm{C}$ in nutrient broth. Active cultures for experiments were prepared by transferring a 
loopful of cells from the stock cultures to test tubes of nutrient broth for bacteria that were incubated without agitation for $24 \mathrm{~h}$ at $37^{\circ} \mathrm{C}$.

\section{Preparation of media}

Media was prepared by dissolving $0.5 \%$ Peptone, $0.3 \%$ beef extract/yeast extract, $1.5 \%$ agar, $0.5 \% \mathrm{NaCl}$ and dissolved in 100 $\mathrm{ml}$ distilled water and autoclaved at $121^{\circ} \mathrm{C}$ for $15 \mathrm{~min}$.

\section{Antibacterial susceptibility test}

Standard well diffusion method was carried out to screen the antibacterial activity. In vitro antibacterial activity was screened by using nutrient agar media. The nutrient agar plates were prepared by pouring $10 \mathrm{ml}$ to $15 \mathrm{ml}$ of molten liquid media into sterile Petri plates. The plates were allowed to solidify for a few minutes and $0.1 \%$ inoculum suspension was swabbed uniformly and the inoculum was allowed to dry for $10 \mathrm{~min}$. wells were prepared on agar plates and $100 \mu 1$ extract and solvent in control well was inoculated and the plates were kept for incubation at $37^{\circ} \mathrm{C}$ for 24 $\mathrm{h}$. At the end of incubation, inhibition zones formed around the wells were measured with transparent ruler in millimeter.

\section{Results and Discussion}

In the present investigation, in vitro antibacterial activity of the crude extracts of three plants was qualitatively assessed on the basis of the inhibition zone. The inhibition effect on growth of $S$. aureus, $P$. aeruginosa and $E$. coli by three extracts of $A$. aspera, $A$. pinnata, and $C$. quadrangularis (Table 1, Fig. 1, 2 and 3.), the results showed that the plant extracts were specific in action against the growth of bacteria. The zone of inhibition of solvents (control) was negligible. Against $S$. aureus in the zone of inhibition was
$20 \pm 0.5 \mathrm{~mm}, 20 \pm 0.9 \mathrm{~mm}$ and $25 \pm 1.3 \mathrm{~mm}$ by ethyl acetate extract of $A$. aspera, A. pinnata, and $C$. quadrangularis respectively. On comparison of mean values the $C$. quadrangularis exhibited maximum antibacterial activity in ethyl acetate extract. In methanol extract of $A$. aspera, A. pinnata, and $C$. quadrangularis the zone of inhibition against $S$. aureus was $11 \pm 0.61 \mathrm{~mm}$, $10 \pm 0.14 \mathrm{~mm}$ and $10 \pm 0.5 \mathrm{~mm}$ respectively. On comparison of mean values the methanol extract of $A$. aspera exhibited maximum antibacterial activity followed by methanol extract of $A$. pinnata. The minimum zone of inhibition was observed in methanol extract of $C$. quadrangularis. In benzene extract of selected three plants diminutive growth of $\mathrm{S}$. aureus was observed.

The zone of inhibition against $P$. aeruginosa was $11 \pm 0.52 \mathrm{~mm}, 11 \pm 0.3 \mathrm{~mm}$ and $13 \pm 0.5 \mathrm{~mm}$ in ethyl acetate extract of $A$. aspera, $A$. pinnata and $C$. quadrangularis respectively. On comparison of mean value it was observed that the highest antibacterial activity was showed by ethyl acetate extract of $C$. quadrangularis followed by $A$. pinnata. In methanol extract of $A$. aspera, A. pinnata, and $C$. quadrangularis the zone of inhibition against $P$. aeruginosa was $12 \pm 0.7 \mathrm{~mm}$, $10 \pm 0.1 \mathrm{~mm}$, and $16 \pm 0.4 \mathrm{~mm}$ respectively. $P$. aeruginosa was most sensitive for the methanol extract of $C$. quadrangularis followed by methanol extract of A. aspera. The antibacterial activity against $P$. aeruginosa by methanol extract of $A$. pinnata was found minimum. A little growth of $P$. aeruginosa was reported in benzene extract of all selected three plants. Against E. coli the zone of inhibition was $13 \pm 0.7 \mathrm{~mm}, 15 \pm 0.5 \mathrm{~mm}$ and $11 \pm 0.6 \mathrm{~mm}$ by ethyl acetate extract of $A$. aspera, A. pinnata, and C. quadrangularis respectively. E. coli was more sensitive to the ethyl acetate extract of $A$. pinnata followed by $A$. aspera and $C$. quadrangularis. 
Table.1 Mean inhibitory ( $\mathrm{mm}$ ) values by the various crude extract of three medicinal plants against tested microorganism

\begin{tabular}{|l|l|l|l|c|c|c|c|c|c|c|}
\hline \multirow{2}{*}{ Bacterial organism } & \multicolumn{3}{|c|}{ A. aspera } & \multicolumn{3}{c|}{ A. pinnata } & \multicolumn{3}{c|}{ C. quadrangularis } \\
\cline { 2 - 11 } & EA & M & B & EA & M & B & EA & M & B \\
\hline S. aureus & $20 \pm 0.5$ & $11 \pm 0.61$ & - & $20 \pm 0.9$ & $10 \pm 0.14$ & - & $25 \pm 1.3$ & $10 \pm 0.5$ & -- \\
\hline P. aeruginosa & $11 \pm 0.52$ & $12 \pm 0.7$ & - & $11 \pm 0.3$ & $10 \pm 0.1$ & - & $13 \pm 0.5$ & $16 \pm 0.4$ & -- \\
\hline E. coli & $13 \pm 0.7$ & $12 \pm 0.8$ & - & $15 \pm 0.5$ & $11 \pm 0.1$ & - & $11 \pm 0.6$ & $13 \pm 0.5$ & -- \\
\hline
\end{tabular}

*EA= Ethyl acetate, $\mathrm{M}=$ Methanol, $\mathrm{B}=$ Benzene

\# Results are mean of triplicate

Fig.1 Antibacterial activity against $S$. aureus by various extract of plant $C$. quadrangularis (Ci), A. aspera (Ac) and A. pinnata (Az)

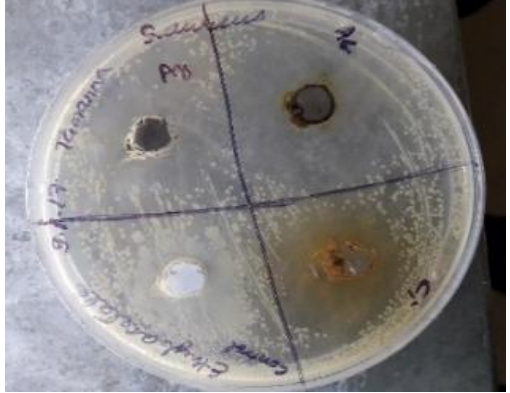

$\mathrm{Ci}, \mathrm{Ac}$ and $\mathrm{Az}$ in ethyl acetate extract

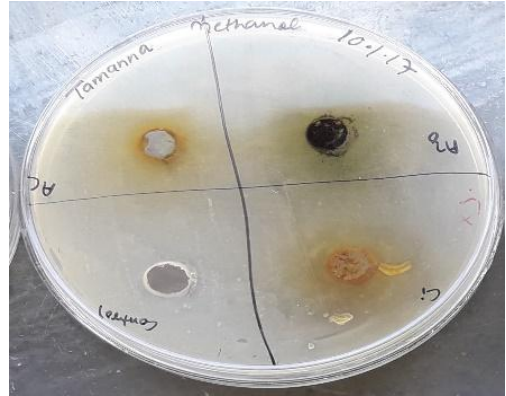

$\mathrm{Ci}, \mathrm{Ac}$ and $\mathrm{Az}$ in methanol extract

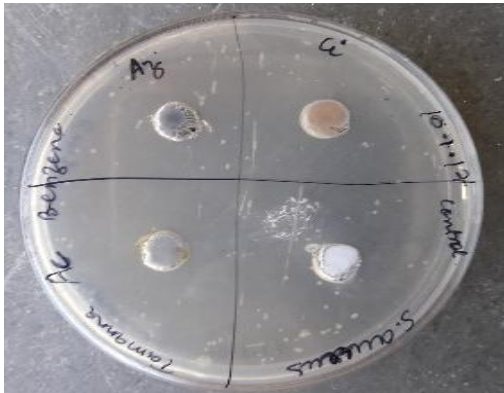

$\mathrm{Ci}, \mathrm{Ac}$ and $\mathrm{Az}$ in benzene extract

Fig.2 Antibacterial activity against $P$. aeruginosa by various extract of plant $C$. quadrangularis (Ci), A. aspera (Ac) and A. pinnata (Az)

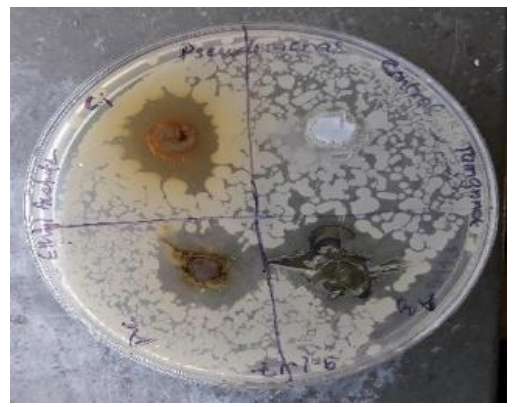

$\mathrm{Ci}, \mathrm{Ac}$ and $\mathrm{Az}$ in ethyl acetate extract

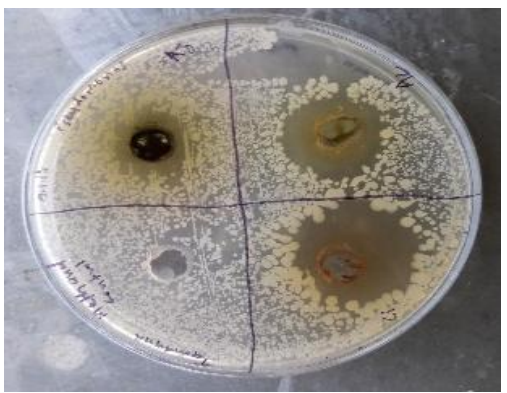

$\mathrm{Ci}, \mathrm{Ac}$ and $\mathrm{Az}$ in methanol extract

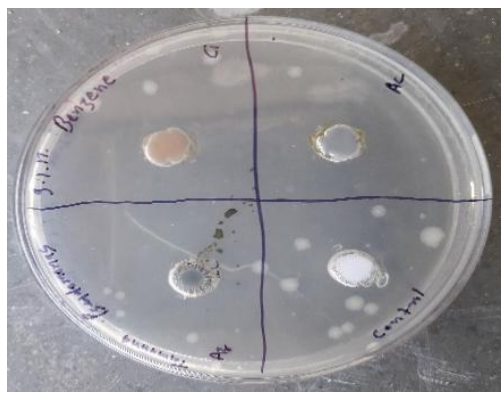

$\mathrm{Ci}, \mathrm{Ac}$ and $\mathrm{Az}$ in benzene extract 
Fig.3 Antibacterial activity against $E$. coli by various extract of plant $C$. quadrangularis (Ci), $A$. aspera (Ac) and A. pinnata (Az)

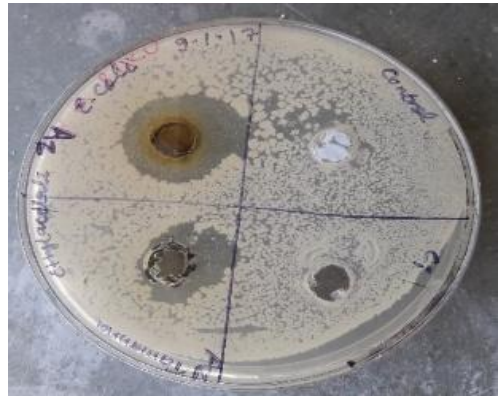

$\mathrm{Ci}, \mathrm{Ac}$ and $\mathrm{Az}$ in ethyl acetate extract

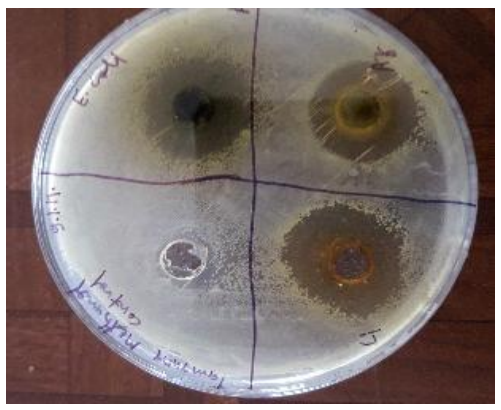

$\mathrm{Ci}, \mathrm{Ac}$ and $\mathrm{Az}$ in methanol extract

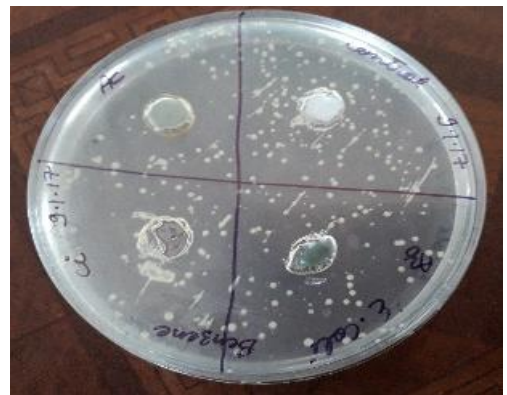

$\mathrm{Ci}, \mathrm{Ac}$ and $\mathrm{Az}$ in benzene extract
The minimum antibacterial activity was reported by ethyl acetate extract of $C$. quadrangularis against $E$. coli. In methanol extract of $A$. aspera, $A$. pinnata, and $C$. quadrangularis the zone of inhibition against E. coli was $12 \pm 0.8 \mathrm{~mm}, 11 \pm 0.1 \mathrm{~mm}$ and $13 \pm 0.5 \mathrm{~mm}$ respectively. The highest zone of inhibition against $E$. coli was showed by methanol extract of $C$. quadrangularis followed by $A$. aspera and $A$. pinnata. In benzene extract of all selected three plants there were little bacterial colonies of E. coli was observed.

In conclusion the plants parts antibacterial effectiveness on the tested bacterial isolates resulted within $24 \mathrm{~h}$ of incubation in all the crude extract screening. From the result obtained it can be concluded that ethyl acetate and methanol extracts of Cissus as well as all the plants have a marked antimicrobial activity against all microorganism tested. The ethyl acetate extracts of the plants displayed extensively a competitive inhibitory potency with the more effective methanol and benzene extracts of the plants selected on the tested isolates. The result of this study also supports the traditional application of the plant and suggests that the plant extracts possess compounds with antibacterial properties that can be used as antibacterial agents in novel drugs for the treatment of various diseases and hence can be exploited for future natural plant based antimicrobial agents.

\section{Acknowledgement}

Authors are thankful to Dr. Dharmesh Harwani, Jyotsna Begani, and Head, Department of Microbiology, MGSU, Bikaner for providing all the facilities and to UGC, New Delhi to provide the fund to pursue this research work.

\section{References}

Bagavan, A., Rahuman, A.A., Kamaraj, C. and Geetha, K. 2008. Larvicidal activity of saponin from Achyranthes aspera against Aedes aegypti and Culex quinquefasciatus (Diptera: Culicidae. Parasitol. Res., 103(1): 223-229.

Elumalai, E.K., Chandrasekaran, N., Thirumalai, T., Sivakumar, C., Viviyan Therasa, S. and David, E. 2009. Achyranthes aspera leaf extracts inhibited fungal growth, Int. J. Pharm. Tech. Res., 1(4): 1576-1579.

Lakshmi Naidu, P.V., Kishore Kumar, K., Mohan Kumar, C., Gunesh, G. and Narasimha Rao, M. 2006. Antimicrobial 
activity of Achyranthes aspera. Biotechnol. Res. Asia, 3(1): 171-174.

Luseba, D., Elgorashi, E.E., Ntloedibe, D.T. and Van Staden, J. 2007. Antibacterial, anti-inflammatory and mutagenic effects of some medicinal plants used in South Africa for the treatment of wounds and retained placenta in livestock. South African J. Bot., 73(3): 378-383.

Mithraja, M.J., Marimuthu, J., Mahesh, M., Paul, Z.M. and Jeeva, S. 2011. Phytochemical studies on Azolla pinnata $R$. Br., Marsilea minuta $L$. and
Salvinia molesta Mitch. Asian Pacific J. Trop. Biomed., 1(1): S26-S29.

Nair, R., Kalariya, T. and Chanda, S. 2005. Antibacterial activity of some selected Indian medicinal flora. Turkish J. Biol., 29(1): 41-47.

Pakrashi, A. and Bhattacharya, N. 1977. Abortifacient principle of Achyranthes aspera Linn. Indian J. Experimental Biol., 15(10): 856-858.

Yadav, R.N.S. and Agarwal, M. 2011. Phytochemical analysis of some medicinal plants. J. Phytol., 3(12): 1014.

\section{How to cite this article:}

Tamanna Talreja, Mangesh Kumar, Asha Goswami and Tribhuwan Sharma. 2017. In vitro Screening of Antibacterial Potentials of Achyranthes aspera Azolla pinnata and Cissus quadrangularis. Int.J.Curr.Microbiol.App.Sci. 6(4): 483-488. doi: https://doi.org/10.20546/ijcmas.2017.604.057 